\title{
Dietary lipids and the inflammatory response
}

\author{
R. F. Grimble \\ Institute of Human Nutrition, University of Southampton, Southampton SO16 7PX, UK
}

Inflammation is an important process in the response of the body to tissue injury and invasion by pathogens. In these contexts, the process is rapid in onset, and recedes once the pathogens are destroyed and damaged tissue has been repaired.

Inflammatory and immune processes are mediated and controlled by a diverse range of molecules. Among these molecules are: proteins; the pro-inflammatory cytokines, tumour necrosis factor (TNF) and interleukins (IL)-1 and -6; derivatives from membrane phospholipids; the eicosanoids (prostaglandins (PG), leukotrienes (LT)); diacylglycerol and ceramide; miscellaneous compounds such as cAMP, inositol phosphates and reactive oxygen species.

The pro-inflammatory cytokines are predominantly products of the immune system; however, endothelial cells and fibroblasts also have the capability for production. Biologically, TNF acts as a trigger which activates a cascade of cytokine production. The molecule is released rapidly in response to inflammatory and infective agents, and induces production of a large number of other cytokines, including IL-1 and IL-6 with which it shares a number of actions in common (Akira et al. 1990). These include generation of a fever, reactive oxygen species and acute-phase protein production, muscle proteolysis, hyperglycaemia, hyperlipidaemia, up-regulation of adhesion molecules and changes in the plasma concentrations of cations (Fig. 1; Tracey \& Cerami, 1993; Grimble, 1996). TNF, by induction of the chemokine IL-8, may also prolong the inflammatory process (Standiford et al. 1990a,b). TNF can further modulate immunological events by induction of IL-1, which stimulates IL-2 and IL-4 production; the latter two cytokines

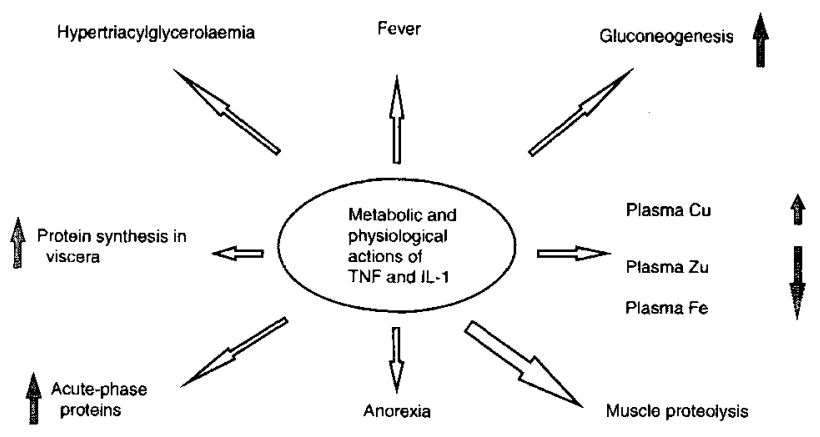

Fig. 1. The metabolic effects of pro-inflammatory cytokines. IL-1, interleukin-1, TNF, tumour necrosis factor- $\alpha$. result in increased lymphocyte proliferation and switching of immunoglobulin classes respectively (Chretien et al. 1990). TNF, in addition to its important role as an early effector in inflammatory and immune processes, is important in killing fungi and a number of viruses (Ito \& O'Malley, 1987). However, this cytokine can enhance human immunodeficiency virus replication (Shreck et al. 1991). Excessive or biologically inappropriate TNF production is closely associated with pathological events. Such events have been closely linked with mortality from cerebral malaria, endotoxic shock, sepsis and adult respiratory distress syndrome, and with pathology in a wide range of disorders (Tracey \& Cerami, 1993). These include rheumatoid arthritis, inflammatory bowel disease, psoriasis and atherosclerosis (Grimble, 1996).

A number of systems and molecules limit TNF and IL-1 production and down-regulate their effects. These regulatory agents have been reviewed elsewhere, and include glucocorticoids, acute-phase proteins, eicosanoids and soluble receptors (Grimble, 1996). External intervention is necessary, however, in situations where TNF production is disadvantageous to the host. Modulation of this nature can be achieved by nutrients and drugs.

Lipids have been shown to be potent modulators of inflammation, a not unsurprising fact since a large number of the modulatory compounds cited previously are derived from the hydrolysis of membrane phospholipids by the action of phospholipase $\mathrm{A}_{2}$ (EC 3.1.1.4; $\mathrm{PG}$ and $\mathrm{LT}$ ), phospholipase $\mathrm{C}$ (EC 3.1.4.3; diacylglycerol), phospholipase D (EC 3.1.4.4; phosphatidic acid) and sphingomyelinases (ceramide).

The fats consumed in diets contain widely-differing amounts and proportions of unsaturated fatty acids. Saturated animal fats, such as those of beef, lamb and butter, contain low concentrations of the $n-6$ polyunsaturated fatty acid (PUFA) linoleic acid (LA). While coconut oil is poor in LA, all other fats of plant origin are rich in LA. Maize, palm and olive oils and butter contain substantial quantities of the monounsaturated fatty acid oleic acid (OA). Oils from fatty fish are rich in the long-chain $n$-3 PUFA eicosapentaenoic acid (EPA) and docosahexaenoic acid. The $n-3$ PUFA linolenic acid (LNA) can act as a precursor for EPA and docosahexaenoic acid. LNA is derived from leafy vegetables, although none are particularly rich in this nutrient.

The most-likely site in the cell where lipids might modulate inflammation is the cell membrane. Dietary unsaturated fatty acids can alter the composition of the fatty acyl chains

\footnotetext{
Abbreviations: EPA, eicosapentaenoic acid; IL, interleukin; LA, linoleic acid; LNA, linolenic acid; LPS, lipopolysaccharide; LT, leukotriene; OA, oleic acid;

PG, prostaglandin; PUFA, polyunsaturated fatty acid; TNF, tumour necrosis factor.

Corresponding author: Professor R. F. Grimble, fax +44(0)1703 594383, email rfg@soton.ac.uk
} 
of membrane phospholipids. Fatty acids may be incorporated into any of the various classes of phospholipids within the membrane, phosphatidylcholine, phosphatidylethanolamine, phosphatidylserine, phosphatidylinositol and sphingomyelin. Thus, the nature of the substrate for PG, LT, diacylglycerol, phosphatidic acid and ceramide production may be changed. The changes in fatty acid composition may also exert a biophysical influence on membrane structure by altering the fluidity characteristics of the membrane. Theoretically, changes in fluidity may influence the activity of membrane-associated enzymes important in controlling cytokine production, e.g. G proteins, and also the affinity with which cytokines bind to their respective receptors in the membrane (Stubbs \& Smith, 1984).

\section{Influence of fats on responses to inflammatory agents and diseases}

In theory, fats may influence inflammation by altering the production of cytokines and other inflammatory mediators, or by changing the sensitivity of target tissues to inflammatory mediators, or by acting at both levels. Thus, studies have investigated the influence of lipids on the responses of animals to bacteria, bacterial extracts, burns and other forms of injury, and injections of recombinant pro-inflammatory cytokines. In addition, studies have examined the effects of lipids on in vivo and in vitro pro-inflammatory cytokine production by cells of the immune system. The ability of lipids to modify the gross inflammatory process in both animal models and disease states in man has also been studied.

\section{Influence of fats on responses to pro-inflammatory cytokines and inflammatory agents}

Numerous studies have shown that fats rich in $n-3$ PUFA exert a generalized anti-inflammatory influence. Guineapigs fed on fish oil for 6 weeks experienced a smaller fever in response to IL-1, than animals fed on safflower oil (Pomposelli et al. 1989). Similarly rats fed on fish oil exhibited a lesser degree of anorexia in response to IL-1 than animals fed on maize oil (Hellerstein et al. 1989). Feeding rats on fish oil, coconut oil or butter for 8 weeks greatly reduced the anorexia experienced following an injection of TNF (Mulrooney \& Grimble, 1993). Thus, fats with a low content of LA (butter and coconut oil) or rich in EPA (fish oil) reduced those responses to IL-1 and TNF that are mediated by the hypothalamus and are known to involve PG. Indeed, Bibby \& Grimble (1990) demonstrated that hypothalamic slices from rats fed on coconut oil, which is poor in LA, produced less $\mathrm{PGE}_{2}$ in response to TNF or endotoxin than slices from rats fed on maize oil, which is rich in LA. While coconut oil, butter and fish oil had similar influences on the anorectic response to TNF in rats, they had different modulatory influences on the effect of the cytokine on liver and lung protein synthesis (Mulrooney \& Grimble, 1993). Animals fed on maize oil experienced an increase in the rate of synthesis in both tissues. However, while fish oil feeding suppressed this response in lung, it had no influence on liver. Butter consistently suppressed responses in both tissues, and coconut oil prefeeding caused a small suppression in liver, but enhanced the response in lung. The changes in plasma concentrations of caeruloplasmin ( $E C$ 1.16.3.1) paralleled the rate of hepatic protein synthesis (Mulrooney \& Grimble, 1993). Thus, cytokine responses that are mediated by PG and LT are, in general, modulated by butter, fish oil and coconut oil in a manner consistent with the LA or EPA content of these fats. However, this is not so for the modulatory effects of the same fats on the actions of TNF on visceral protein metabolism. This is not unexpected, since there is substantial evidence against direct involvement of PG and LT in visceral protein responses to cytokines. Cyclooxygenase ( $E C$ 1.14.99.1) inhibitors are ineffective at inhibiting the increase in C-reactive protein following endotoxin injection in human volunteers. Similarly, the increased rate of non-secretory protein synthesis by liver of rats given endotoxin or IL-1 is not prevented by ibuprofen (Kunkel et al. 1987). Furthermore, increases in glycosaminoglycan synthesis in lung fibroblasts stimulated with TNF were unaffected by indomethacin (Elias et al. 1988). Thus, alternative mechanisms have to be sought for the modulatory effects of fats on the responses of visceral protein synthesis to cytokines.

Olive oil and butter, which like coconut oil have a low content of LA, almost without exception suppress both the effects of inflammatory agents which are clearly modulated by eicosanoids, and those which are not. The effects include anorexia, the fall in body temperature, elevation of plasma caeruloplasmin concentrations, and an increase in liver protein and $\mathrm{Zn}$ content and in protein synthetic rates in liver, lung and kidney (Besler \& Grimble, 1995). Thus, olive oil and butter possess other fatty acid characteristics, apart from a low LA content, which bestow anti-inflammatory properties. OA content is the most obvious characteristic, comprising $(\mathrm{g} / 100 \mathrm{~g}$ fat) 22 and 69 in butter and olive oil respectively, but only 6 in coconut oil. The addition of OA to coconut oil in an amount similar to that in butter prevented the stimulatory effect of the oil on lung protein synthetic rates (Grimble, 1992).

Addition of 50,100 or $200 \mathrm{~g}$ olive oil $/ \mathrm{kg}$ to the diet of rats almost totally suppressed metabolic responses to a lipopolysaccharide (LPS) injection, emphasizing the potential anti-inflammatory influence of OA (Besler \& Grimble, 1995). Conversely, diets rich in LA had a pro-inflammatory influence in animal models of inflammation. The inflammatory response to burn injury in guinea-pigs was enhanced by safflower oil when it constituted $30-50 \%$ of the dietary energy (Alexander et al. 1986). In rats the degree of anorexia, fall in body temperature, elevation of caeruloplasmin and increase in liver protein and $\mathrm{Zn}$ content in response to endotoxin injections was increased in a stepwise manner when maize oil was included in their diets in amounts of 50, 100 and $200 \mathrm{~g} / \mathrm{kg}$ (Besler \& Grimble, 1995).

Although OA is capable of inhibiting incorporation of LA and arachidonic acid into membrane phospholipids, it is improbable that it is exerting its influence on visceral protein responses by modulating eicosanoid metabolism. In vitro studies have shown that $\mathrm{OA}$ is able to activate protein kinase $\mathrm{C}$, which has been implicated in the down-regulation of receptors for TNF (Ungloub et al. 1987; Khan et al. 1992).

Studies on the modulatory influence of butter on responses to LPS indicate that while the fat may exert an anti-inflammatory influence due to its low $n$-6 PUFA and high OA content, when fed in high concentrations $(200 \mathrm{~g} / \mathrm{kg})$ 
it loses this influence due to the amount of cholesterol which it provides. While diets containing butter at $100 \mathrm{~g} / \mathrm{kg}$ suppressed a wide range of responses to LPS, a diet containing an identical amount of the fat, but to which cholesterol had been added to bring the total dietary content $(0.23 \mathrm{~g} / \mathrm{kg})$ to that which would occur from the inclusion of $200 \mathrm{~g}$ butter $/ \mathrm{kg}$, permitted responses to LPS (Besler \& Grimble, 1994a). Cholesterol may exert a pro-inflammatory effect by enhancing cytokine production. Studies on rabbits show that IL-1 and TNF synthesis in the aorta wall in response to an LPS injection was enhanced by inclusion of cholesterol $(3 \mathrm{~g} / \mathrm{kg}$ ) in diets containing maize oil (Fleet et al. 1992).

Cholesterol may also exert a more generalized proinflammatory effect. In in vitro studies on monocytes, Hughes et al. (1992) showed that incubation with cholesterol increased expression of human major histocompatibility complex D sub-region products. Cholesterol was also shown to increase the proliferative response of human peripheral blood lymphocytes to phytohaemagglutinin (Wilsher et al. 1988).

In summary, it would seem that the intensity of the multiplicity of metabolic changes, which are part of the inflammatory process, is influenced by the unsaturated fatty acid and cholesterol content of the diet. While $n-6$ PUFA and cholesterol exert a pro-inflammatory influence, $n-3$ PUFA and monounsaturated fatty acids exert the opposite effect.

\section{Influence of fats on cytokine production}

Relatively few studies have examined the modulatory effects of lipids on the ability of cells to produce cytokines. Those that have been carried out have examined cytokine secretion alone, and have not examined mRNA expression. In human volunteers, supplementation of the diet for 6 weeks with $18 \mathrm{~g}$ of a fish oil concentrate rich in EPA and docosahexaenoic acid reduced the ability of monocytes to produce IL- $1 \alpha$ and $\beta$ and TNF- $\alpha$ by at least one-third. The effect was still evident 10 weeks after cessation of dietary supplementation (Endres et al. 1989). A similar suppressive effect of dietary supplementation with fish oil on IL-1 production by stimulated monocytes was noted in rheumatoid patients (Kremer \& Robinson, 1991), and on IL-1, IL-6 and TNF production in young and old women (Meydani, 1992). In the study on rheumatoid patients (Kremer \& Robinson, 1991), olive oil supplements were given to the control group; a fall in ability to produce IL-1 was noted in this group also. The effect did not reach statistical significance; however, the effect is interesting in view of the anti-inflammatory nature of olive oil in animal studies, and the suggestion that rheumatoid arthritis is less common in Mediterranean regions of Europe than elsewhere (Linos et al. 1991).

We examined the ability of TNF to induce IL-1 and IL-6 production by peritoneal macrophages from rats fed for 4 and 8 weeks on a range of fats representing the wide range of types encountered in human diets. The fats studied were maize, olive, coconut and fish oils and butter; chow-fed animals were included in the studies. Complex modulation occurred (Tappia \& Grimble, 1994). After 4 weeks fish and olive oils suppressed IL-1 production (relative to chow-fed animals). However, after 8 weeks, while fish and coconut oils suppressed IL-1 production, olive oil and maize oil enhanced production. After 4 weeks IL-6 production was enhanced by fish and olive oils, and after 8 weeks all the fats except coconut oil had resulted in enhanced production. However, despite the complexity of these effects, after 8 weeks of receiving the diets, there was a positive relationship between production of IL- 1 and the $n-6$ PUFA intake of the animals and between IL-6 production and the total intake of unsaturated fatty acids (Grimble \& Tappia, 1995). The study in rats was partly paralleled by the results of a study of the influence of a cholesterol-lowering diet on immune function of middle-aged subjects (Meydani et al. 1993). A change in $n$-6 PUFA intake from 6.6 to $8.8 \%$ of the dietary energy resulted in a 62 and $47 \%$ increase respectively in IL-1 and TNF production from stimulated monocytes. Addition of $0.54 \%$ of the dietary energy as $n-3$ PUFA counteracted this effect, and resulted in decreases of 40 and $7 \%$ respectively in the production of the two cytokines.

\section{Influence of fats on inflammatory disease in animal models and human subjects}

Clinical studies have concentrated on the effects of fish oil, while the influence of a range of fats has been studied in animal models of inflammation.

Inflammatory symptoms in rheumatoid arthritis, psoriasis, asthma, Crohn's disease and ulcerative colitis are ameliorated by fish oil (Grimble, 1992; Calder, 1997). The substantial weight loss which occurs in pancreatic cancer is prevented by a daily supplement of fish oil (Barber $e t$ al. 1998).

There are many animal models of acute and chronic inflammation. Fats have been shown to modulate these processes. Fish oil protected pigs, rats and guinea-pigs from the lethal effects of endotoxin. The oil exerted protective effects in experimental colitis in rats. The oil also reduced the metabolic response to burn injury in guinea-pigs, the number of polymorphonuclear cells in air pouches of rats challenged with bovine serum albumin, and the degree of anorexia and weight loss in mice given the MAC16 colon adenocarcinoma. Diets rich in medium-chain triacylglycerols produced similar ameliorative effects in the same cancer cachexia model (Wallace et al. 1980; Johnston, 1985; Yoshino \& Ellis, 1987; Grimble, 1992).

\section{Mechanisms whereby fats may modulate production and actions of pro-inflammatory cytokines}

The most likely manner in which lipids might modulate pro-inflammatory cytokine biology is by changing the fatty acid composition of the fatty acyl chains of the phospholipids in cell membranes. The fatty acids compete for incorporation into the phospholipid structure. The affinity for incorporation is in the order LNA > LA > OA. Furthermore, dietary arachidonic acid and EPA may be incorporated into phospholipids. EPA is incorporated with the highest affinity of all unsaturated fatty acids (Johnston, 1985; Murphy, 1990). Conversion of the $n-3, n-6$ and $n-9$ fatty acids to precursors of eicosanoids occurs after they have become attached to the $s n-2$ position of membrane phospholipids.

As a consequence of the changes in the fatty acid component of membrane phospholipids, two interrelated 
phenomena may occur, i.e. alteration in membrane fluidity and in the products which arise from hydrolysis of membrane phospholipids.

Changes in fluidity may alter the binding of cytokines and cytokine-inducing agonists to receptors (Stubbs \& Smith, 1984; Murphy, 1990). They may also alter components of the signal transduction process which leads to cytokine production or its effects; for example, fluidity changes may alter $G$-protein activity, thereby changing adenylate cyclase $(E C$ 4.6.1.1), phospholipase $\mathrm{A}_{2}$ and phospholipase $\mathrm{C}$ activity. Alterations in membrane phospholipids will also directly influence the synthesis of lipid-derived mediators such as the eicosanoids, diacylglycerol, phosphatidic acid, ceramide and platelet-activating factor. The fatty acid composition of all but the first of these mediators will reflect membrane phospholipid composition. The pattern of eicosanoid production will be influenced by the fatty acid incorporated into the $s n-2$ position, as activation of phospholipase $\mathrm{A}_{2}$ will release fatty acid from this location for eicosanoid synthesis. The position is usually occupied by unsaturated fatty acids. Arachidonic acid is the parent compound of PG and LT of the 2 and 4 series respectively, while EPA is the precursor of

\section{(a)}

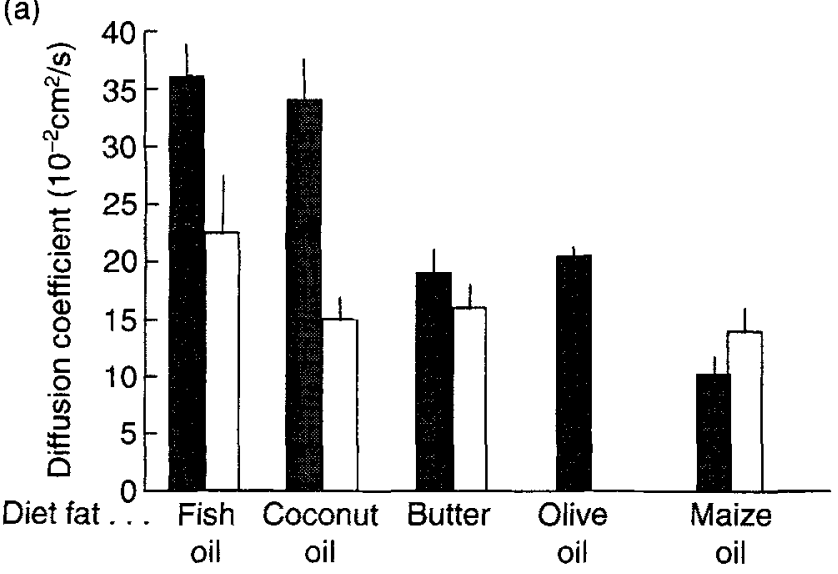

(b)

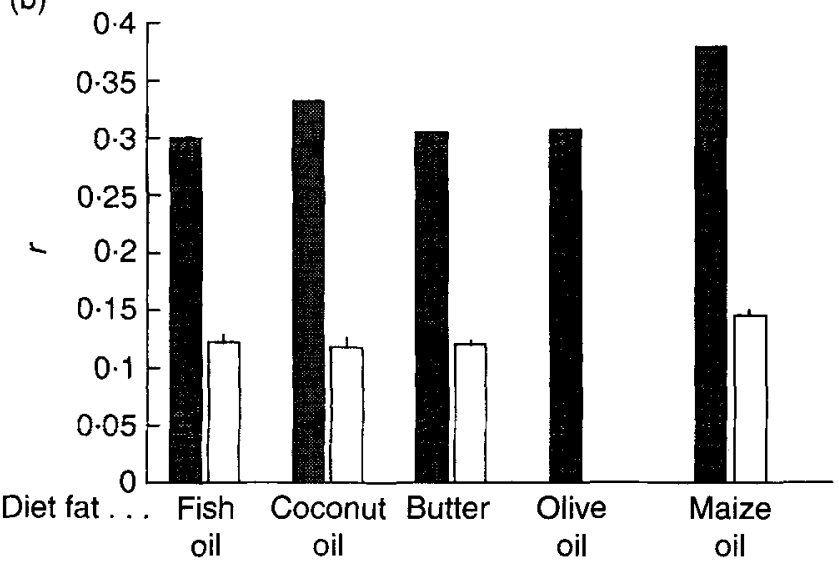

Fig. 2. The influence of fats of differing unsaturated fatty acid contents on lateral and rotational fluidity of membranes of hepatocytes () and peritoneal macrophages ( $\boldsymbol{\sigma})$, measured by (a) the fluorescence recovery after photobleaching and (b) diphenylhydrazine anisotropic methods respectively (Tappia et al. 1997). Values are means with their standard errors represented by vertical bars. the less-potent PG and LT of the 3 and 5 series respectively. Eicosatetraenoic acid only acts as an eicosanoid substrate under conditions of essential fatty acid deficiency. Dietary fat composition may thus modulate the proportions of all three eicosanoid precursors.

Influence of dietary fat on membrane fluidity in cells producing and responding to pro-inflammatory cytokines

Agents which alter membrane fluidity of lymphocytes have been shown to inhibit IL-2 production. However, both ethanol which increases fluidity, and sterols which decrease fluidity, produce this effect (Tappia \& Grimble, 1994). Moreover, inclusion of cholesterol in the diets of rabbits which might be expected to reduce membrane fluidity, enhanced IL-1 and TNF expression in aortas (Fleet et al. 1992).

To investigate whether dietary fats change inflammatory processes via alterations in membrane fluidity, we (Tappia et al. 1997) have examined the effect of feeding a wide range of fats on the lateral fluidity (measured by the fluorescence recovery after photobleaching technique) and rotational fluidity (measured by diphenylhydrazine anisotropy) of membranes from rat peritoneal macrophages and hepatocytes. The results are illustrated in Fig. 2( $\mathrm{a}$ and $\mathrm{b}$ ). In general, fluidity assessed by either method was influenced in a similar manner in membranes from both types of cell. There was, however, no consistent relationship between membrane fluidity and the intensity of inflammation. Fish and coconut oils resulted in high lateral fluidity, and suppressed proinflammatory cytokine production and responsiveness of tissues to inflammatory agents. However, butter and maize oil resulted in low lateral fluidities, but had opposing effects on the indices of inflammation. Thus, the precise nature and significance of fat-induced alterations in membrane fluidity in cytokine-producing and cytokine-sensitive cells requires further investigation.

\section{Influence of n-6 polyunsaturated fatty acid intake and endotoxin on plasma membrane phospholipid class distribution and inflammatory mediator production during inflammation}

To gain a better understanding of how inflammatory mediator production is influenced by dietary fats, we examined the proportions of phospholipid classes in hepatocyte plasma membranes of rats exposed to an injection of LPS after a 4-week period of differing dietary fat intake. To obtain a range of unsaturated fatty acid intakes, the animals were fed on maize oil, olive oil or butter at three concentrations ( 50 , 100 and $200 \mathrm{~g} / \mathrm{kg}$ diet). Liver membrane composition was examined $24 \mathrm{~h}$ after injection. Major changes in plasma membrane composition occurred in response to LPS, which were modulated by the diet (Besler \& Grimble, 1994b). Data are shown in Fig. 3 and are expressed in relation to the LA intake of the dietary groups. Whilst most membrane constituents were unaffected by dietary LA intake, plasma membrane phosphatidylserine was negatively related to LA intake. In response to LPS, large decreases in membrane phosphatidylinositol and phosphatidylcholine occurred. The amount of phosphatidylserine in the membranes increased, as did cholesterol content. A small decrease in phosphatidyl- 

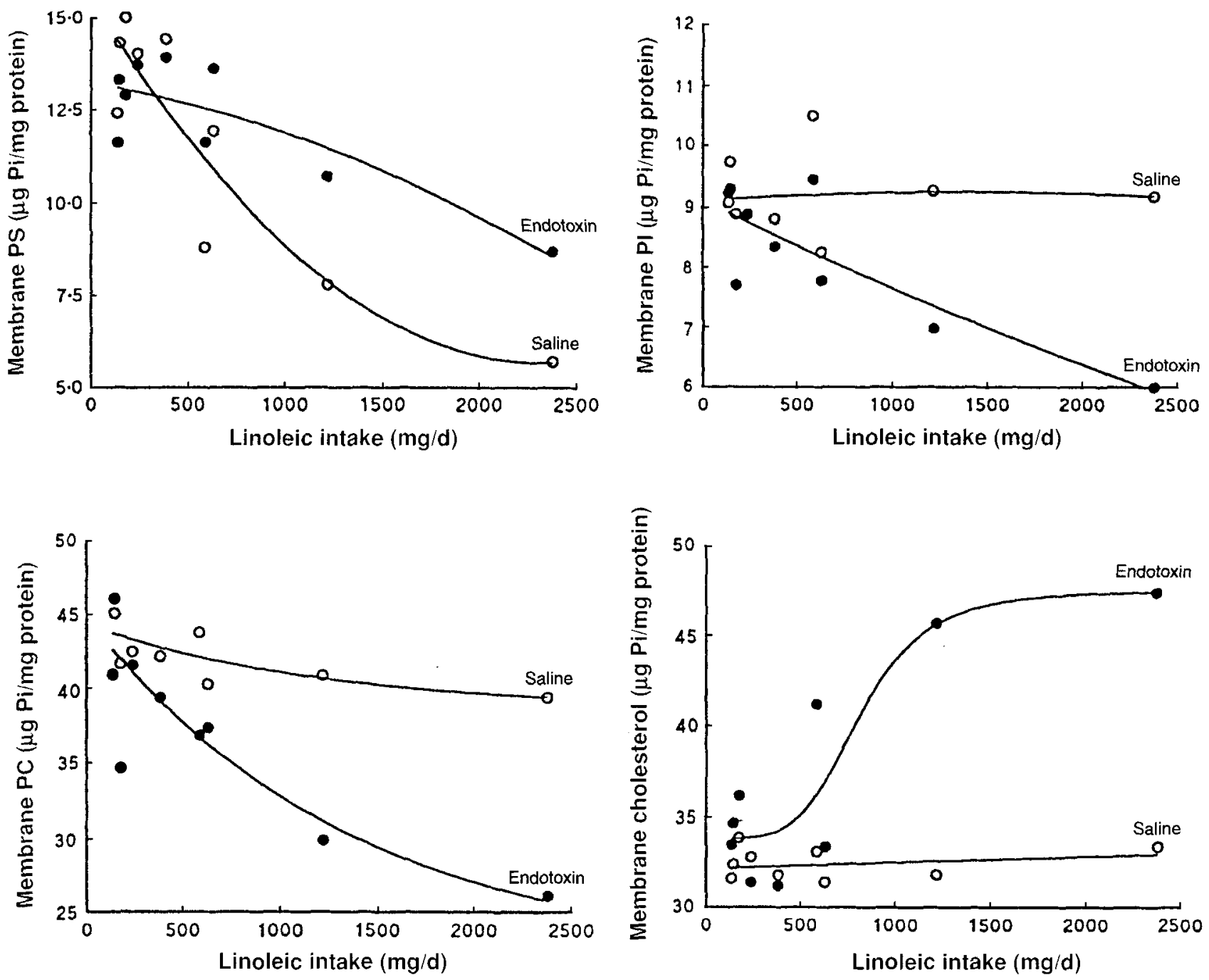

Fig. 3. The influence of linoleic acid intake on hepatocyte plasma membrane phospholipid class concentrations in rats given a saline ( $9 \mathrm{~g}$ NaCl/ ) or lipopolysaccharide injection. Pi, inorganic phosphate; PS, phosphatidylserine; PC, phosphatidylcholine; PI, phosphatidylinositol. (From Grimble \& Tappia, 1998.)

ethanolamine and no change in sphingomyelin occurred (data not shown).

Activation of protein kinase $\mathrm{C}$ requires the hydrolysis of phosphatidylinositol and the presence of phosphatidylserine. The changes that occurred in the composition studies described previously indicate that an increase in both factors occurs in vivo, in response to an inflammatory challenge. Furthermore, the magnitude of the responses increased with dietary LA intake. It is unknown whether similar changes occur in the plasma membrane of macrophages. Should such modulation be the case, then dietary modulation of protein kinase $\mathrm{C}$ activity may, in part, play an important role in the modulation of the ability of TNF to induce IL-1 and IL-6.

During inflammation, the changes in membrane phospholipid content associated with differing LA intakes would suggest altered production of inflammatory mediators such as PG and LT. In vitro studies have shown that PG inhibit and LT stimulate IL-1 production (Dinarello et al. 1984; Kunkel et al. 1987). While both types of eicosanoids are produced from arachidonic acid and EPA, it has been suggested that LT are more potent biological modulators than PG. Thus, incorporation of EPA into membrane phospholipids might be expected to reduce IL-1 production, and arachidonic acid to have the opposite effect. This situation was investigated by examining production of $\mathrm{PGE}_{2}$ and $\mathrm{LTB}_{4}$ by peritoneal macrophages of rats which had been fed on a range of fats with different unsaturated fatty acid contents. When cells were stimulated with LPS, a complex pattern of eicosanoid production occurred (Tappia \& Grimble, 1996). The data presented in Fig. 4 show that $\mathrm{LTB}_{4}$ production is positively related to $n-6$ PUFA intake from diets containing coconut oil, butter, fish oil and olive oil but not from a maize oil diet. $\mathrm{PGE}_{2}$ production is unaffected by LA intake. Thus, the increase in production of eicosanoids is only partially consistent with the increases in membrane phospholipid hydrolysis that are associated with increases in LA intakes.

From the foregoing discussion it can be seen that there is a substantial degree of uncertainty about the mechanisms whereby dietary fats modulate inflammation. There are a 


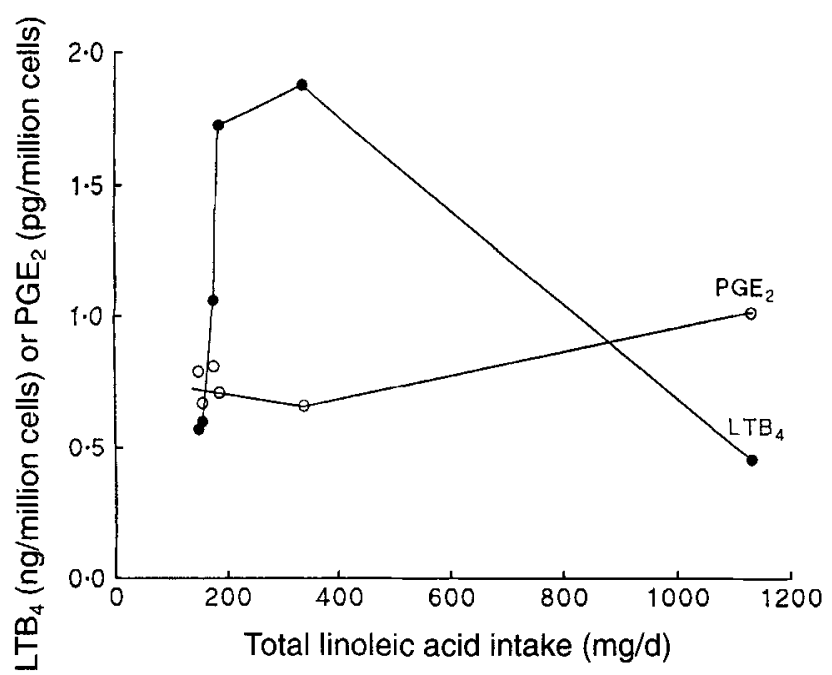

Fig. 4. The influence of dietary linoleic acid intake of rats on prostaglandin $\mathrm{E}_{2}\left(\mathrm{PGE}_{2}\right)$ and leukotriene $\mathrm{B}_{4}\left(\mathrm{LTB}_{4}\right)$ production by peritoneal macrophages stimulated with tumour necrosis factor- $\alpha$. (From Grimble \& Tappia, 1998.)
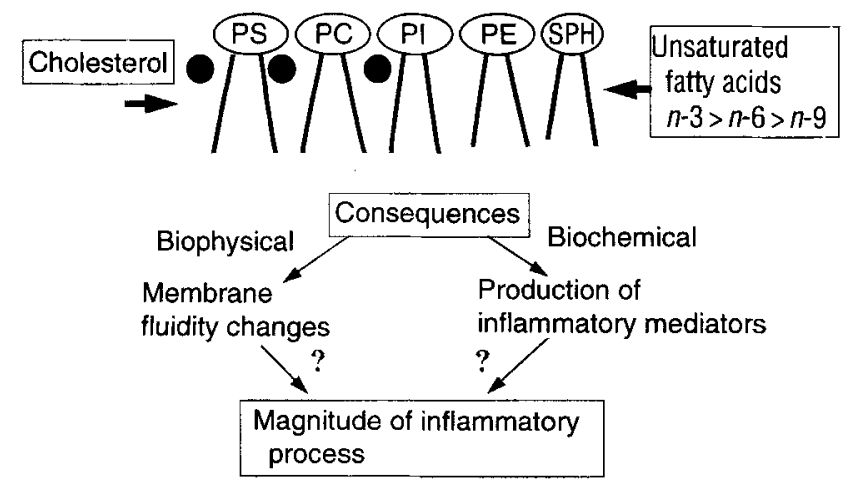

Fig. 5. The potential mechanisms whereby changes in dietary lipid intake modulate inflammation. PS, phosphatidylserine; PC, phosphatidylcholine; PI, phosphatidylinositol; PE, phosphatidylethanolamine; $\mathrm{SPH}$, sphingomyelin.

number of candidate mechanisms on which information is available (Fig. 5). It is certain that fats can modulate inflammation and alter the composition of plasma membranes both in cells producing pro-inflammatory cytokines and in those which are the targets of their actions. The biophysical and biochemical consequences of compositional change have yet to be fully described.

\section{Implications of experimental observations on lipids and inflammation for inflammatory disease in human populations}

With the major decline in infectious disease in populations in industrialized countries, attention has been focused on other diseases in which inflammation plays a part, such as atherosclerosis, rheumatoid arthritis, asthma and inflammatory bowel diseases.

In many industrialized countries, such as the UK, USA and Australia, large increases in the intake of n-6 PUFA have occurred in the last 30 years (Roberts, 1991). In the UK, polyunsaturated fatty acid: saturated fatty acid intake doubled between 1972 and 1988. The intake of n-6 PUFA rose from $4 \%$ of the dietary energy in the early 1970 s to $6 \%$ at present (Department of Health, 1994). It has been suggested that the upsurge of asthma which has been observed in the UK, Australia and New Zealand is related to these increases in PUFA intake (Black \& Sharpe, 1997). The unexplained increase in the incidence of eczema and allergic rhinitis, and regional differences of inflammatory disease within countries, may relate to $n-6$ PUFA intake (Lewis $e t$ al. 1996; Black \& Sharpe, 1997). For example, the incidence of asthma is lower in Scotland and the north of England than in the south, and intakes of $n$ - 6 PUFA are highest in the south of England (Lewis et al. 1996). Similarly, the incidence of asthma was lower in the eastern part of Germany (where intakes of $n-6$ PUFA were lower) than in the western part of the country (where larger quantities of $n-6$ PUFA were consumed; Black \& Sharpe, 1997). In southern Finland, the incidence of asthma in rural children is over three times higher than in children from the industrialized east of the country. The levels of $n$ - 6 PUFA in plasma cholesteryl esters are significantly greater in the former region, thus confirming a higher intake of $n$-6 PUFA (Black \& Sharpe, 1997). In Japan, where a steady increase in fat intake from 16 to $24 \%$ of dietary energy, and a change in the amount of $n-6$ PUFA relative to $n-3$ PUFA in the diet has occurred as a result of 'Westernization of the diet' between 1966 and 1985, major rises in the incidence of Crohn's disease have been observed (Shoda et al. 1996). An epidemiological study reported that an increase in $n$-6 PUFA : $n$-3 PUFA value from 3.3 to 3.8 was associated with a doubling in the number of newlydiagnosed cases of the disease (Shoda et al. 1996).

While the impact of changes in dietary fat intake on the incidence of inflammatory disease in populations has played little part in the recommendations of governmental committees, recommendations from the recent Department of Health (1994) report, although targeted at CHD, may have a beneficial influence on the burden of inflammatory disease in the population. In the document it is recommended that "no further increase in the average intakes of $n-6$ PUFA' occur and that 'the proportion of the population consuming in excess of about $10 \%$ of energy (as $n-6$ PUFA) should not increase'. For $n-3$ PUFA it is recommended that 'the population average consumption of long-chain n-3 PUFA (should increase) from $0.1 \mathrm{~g} / \mathrm{d}$ to about $0.2 \mathrm{~g} / \mathrm{d}$.'

\section{References}

Akira S, Hirano T, Taga T \& Kishimoto T (1990) Biology of multifunctional cytokines: IL6 and related molecules (IL1 \& TNF). FASEB Journal 4, 2860-2867.

Alexander JW, Saito H, Ogle CK \& Trocki O (1986) The importance of lipid type in the diet after burn injury. Annals of Surgery 204, 1-8.

Barber MD, Ross JA \& Fearon KCH (1998) The anti-cachectic effects of fatty acids. Proceedings of the Nutrition Society 57 , 571-576.

Besler HT \& Grimble RF (1994a) Dietary cholesterol may modify the modulatory effects of dietary fats on the metabolic responses to endotoxin in rats. Proceedings of the Nutrition Society 53, 168A.

Besler HT \& Grimble RF (1994b) Effect of endotoxin on liver plasma membrane phospholipid class distribution in rats fed on 
maize and olive oils and butter. Proceedings of the Nutrition Society 53, 181A.

Besler T \& Grimble RF (1995) Comparison of the modulatory influence of maize and olive oils and butter on the metabolic responses to endotoxin in rats. Clinical Science 88, 59-66.

Bibby DC \& Grimble RF (1990) Tumour necrosis factor $\alpha$ and endotoxin induce less prostaglandin E2 production from hypothalami of rats fed coconut oil than from hypothalami of rats fed maize oil. Clinical Science 79, 657-662.

Black PN \& Sharpe S (1997) Dietary fat and asthma: is there a connection? European Respiratory Journal 10, 6-12.

Calder PC (1997) n-3 Polyunsaturated fatty acids and cytokine production in health and disease. Annals of Nutrition and Metabolism 41, 203-234.

Chretien I, Pene J, Briene F, Malefijt R, Rousett F \& DeVries JE (1990) Regulation of human IgE synthesis in vitro is determined by the reciprocal antagonistic effect of interleukin 4 and interferon-gamma. European Journal of Immunology 20, 243-251.

Department of Health (1994a) Nutritional Aspects of Cardiovascular Disease. Report on Health and Social Subjects no. 46. London: HM Stationery Office.

Dinarello CA, Bishai I, Rosenwasser LJ \& Coceani F (1984) The influence of lipoxygenase inhibitors on the in vitro production of human leukocytic pyrogen and lymphocyte activating factor (interleukin 1). International Journal of Immunopharmacology 6, 43-50.

Elias JA, Krol RC, Freundlich B \& Sampson PM (1988) Regulation of human lung fibroblast glycosaminoglycan production by recombinant interferons, tumour necrosis factor and lymphotoxin. Journal of Clinical Investigation 81, 325-333.

Endres S, Ghorbani R, Kelly VE, Georgilis K, Lonnemann G, Van der Meer JWM, Rogers JG, Klempner TS \& Weber PC (1989) The effect of dietary supplementation with $n-3$ polyunsaturated fatty acids on the synthesis of IL1 and TNF $\alpha$ by mononuclear cells. New England Journal of Medicine 320, 266-271.

Fleet JC, Clinton SK \& Saloman RN (1992) Atherogenic diets enhance endotoxin-stimulated interleukin-1 and tumor necrosis factor gene expression in rabbit aortae. Journal of Nutrition 12, 294-298.

Grimble RF (1992) Dietary manipulation of the inflammatory response. Proceedings of the Nutrition Society 51, 285-294.

Grimble RF (1996) Interaction between nutrients, proinflammatory cytokines and inflammation. Clinical Science $\mathbf{9 1}$ 121-130.

Grimble RF \& Tappia PS (1995) The modulatory influence of unsaturated fatty acids on the biology of tumour necrosis factor- $\alpha$. Biochemical Society Transactions 23, 282-286.

Grimble RF \& Tappia PS (1998) Modulation of pro-inflammatory cytokine biology by unsaturated fatty acids. Zeitschrift für Ernahrungswissenschaft 37, Suppl. 1, 57-65.

Hellerstein MK, Meydani SN, Meydani M, Wu K \& Dinarello CA (1989) Interleukin-1-induced anorexia in the rat. Influence of prostaglandins. Journal of Clinical Investigation 84, 228-235.

Hughes DA, Townsend PJ \& Haslam PL (1992) Enhancement of antigen presenting functions of monocytes by cholesterol: possible relevance to inflammatory mechanisms in extrinsic allergic alveolitis and atherosclerosis. Clinical and Experimental Immunology 87, 279-286.

Ito M \& O'Malley JA (1987) Antiviral effect of recombinant human tumour necrosis factor. Lymphokine Research 6, 309-318.

Johnston PV (1985) Dietary fat, eicosanoids and immunity. Advances in Lipid Research 21, 103-141.

Khan WA, Blobe GC \& Hannun YA (1992) Activation of protein kinase $C$ by oleic acid. Journal of Biological Chemistry 267, 3605-3612.
Kremer JM \& Robinson DR (1991) Studies of dietary supplementation with $n-3$ fatty acids in patients with rheumatoid arthritis. World Review of Nutrition and Dietetics 66, 367-382.

Kunkel SL, Remick DG, Spengler M \& Chensue SW (1987) Modulation of macrophage-derived interleukin-1 and tumour necrosis factor by prostaglandin $\mathrm{E}_{2}$. Advances in Prostaglandin Leukotriene and Thromboxane Research 17A, 155-158.

Lewis S, Butland B, Strachen D, Bynner J, Richards D, Butler N \& Britton J (1996) Study of the aetiology of wheezing illness at age 16 in two national British birth cohorts. Thorax 51, 670-676.

Linos A, Kaklamanis E, Kantomerkos A, Koumantaki Y, Gazi S, Viapoulos G, Tsokos GC \& Kaklamanis PH (1991) The effect of olive oil and fish consumption on rheumatoid arthritis: a case control study. Scandinavian Journal of Rheumatology 20, 419-426.

Meydani SN (1992) Modulation of IL1, IL6 and TNF production from monocytes of old and young women fed fish oil. Proceedings of the Society of Experimental Biology and Medicine 200, 189-193.

Meydani SN, Lichtenstein AH, Cornwall S, Meydani M, Goldin R, Rasmussen H, Dinarello CA \& Schaefer EJ (1993) Immunologic effects of National Cholesterol Education Panel Step-2 diets with and without fish-derived $n-3$ polyunsaturated fatty acid enrichment. Journal of Clinical Investigation 92, 105-113.

Mulrooney HM \& Grimble RF (1993) The influence of butter, and corn, coconut and fish oils on the effects of recombinant human tumour necrosis factor $\alpha$ in rats. Clinical Science 84, 105-112.

Murphy MG (1990) Dietary fatty acids and membrane function. Journal of Nutritional Biochemistry 1, 68-79.

Pomposelli JJ, Mascioli EA, Bistrian BR, Lopez SM \& Blackburn GL (1989) Attenuation of the febrile response in guinea pigs by fish oil enriched diets. Journal of Parenteral and Enteral Nutrition 13, 136-140.

Roberts DCK (1991) Dietary factors in the fall in coronary heart disease mortality. Prostaglandins Leukotrienes and Essential Fatty Acids 44, 97-101.

Shoda R, Matsueda K, Yamoto S \& Umeda N (1996) Epidemiologic analysis of Crohn's disease in Japan: increased dietary intake of $n-6$ polyunsaturated fatty acids and animal protein relates to the increased incidence of Crohn's disease in Japan. American Journal of Clinical Nutrition 63, 741-745.

Shreck R, Rieber P \& Baeurerle PA (1991) Reactive oxygen intermediates as apparently widely used messengers in the activation of NFkB transcription factor and HIV-1. EMBO Journal 10, 2247-2256.

Standiford TJ, Kunkel SL, Basha MA, Chensue SW, Lynch JP, Toews GB, Westwick J \& Strieter RM (1990a) Interleukin 8 gene expression by a pulmonary epithelial cell line: A model for cytokine networks in the lung. Journal of Clinical Investigation 86, 1945-1953.

Standiford TJ, Strieter RM, Kasahara K \& Kunkel SL (1990b) Disparate regulation of interleukin 8 gene expression from blood monocytes, endothelial cells and fibroblasts by interleukin 4 . Biochemical and Biophysical Research Communications 171, 531-536.

Stubbs CD \& Smith AD (1984) The modification of mammalian polyunsaturated fatty acid composition in relation to membrane fluidity and function. Biochimica et Biophysica Acta 779, 89-137.

Tappia PS \& Grimble RF (1994) Complex modulation of cytokine induction by endotoxin and tumor necrosis factor alpha from peritoneal macrophages of rats fed by diets containing fats of differing saturated, monounsaturated and polyunsaturated fatty acid composition. Clinical Science 87, 173-178.

Tappia PS \& Grimble RF (1996) The relationship between altered membrane composition, eicosanoids and TNF-induced IL1 and 
IL6 production in macrophages of rats fed fats of different unsaturated fatty acid composition. Molecular and Cellular Biochemistry 165, 135-143.

Tappia PS, Ladha S, Clark DC \& Grimble RF (1997) The influence of membrane fluidity, TNF receptor binding cAMP production and GTPase activity on macrophage cytokine production in rats fed a variety of fat diets. Molecular and Cellular Biochemistry 166, 135-143.

Tracey KJ \& Cerami A (1993) Tumor necrosis factor, other cytokines and disease. Annual Reviews of Cell Biology 9, 317-343.

Ungloub R, Maxeiner B, Thoma B, Pfizenmaier K \& Scheurich P (1987) Down regulation of tumor necrosis factor (TNF) sensitivity via modulation of TNF binding capacity by protein kinase $\mathrm{C}$ activation. Journal of Experimental Medicine 166, 1788-1797.

Wallace JL, Keenan CM \& Finn NJ (1980) Anti inflammatory effects of a fish oil diet in a rat model of chronic colitis. Gastroenterology 96, A83.

Wilsher ML, Hughes DA \& Haslam PL (1988) Immunoregulatory properties of pulmonary surfactant: influence of variation in the phospholipid profile. Clinical and Experimental Immunology 73, $117-122$.

Yoshino S \& Ellis EF (1987) Effects of a fish oil supplemented diet on inflammation and immunological processes in rats. International Archives of Allergy and Applied Immunology 84, 233-240. 